\title{
Culture and Organizational Improvisation in UK Financial Services
}

\author{
Stephen A. Leybourne \\ Boston University, Boston, USA. \\ Email: sleyb@bu.edu \\ Received August 21, 2009; revised October 6, 2009; accepted November 10, 2009.
}

\begin{abstract}
This paper considers certain aspects of a four-year program of research, and addresses the changing cultural requirements to support the rise of improvisational working practices within the UK financial services sector. Specifically, it reports on some of the outcomes of a study encompassing over 100 hours of interviews, together with a variety of other primary and secondary data. The outcomes of the full study are documented elsewhere, and they identify a number of key factors that contribute to the successful use and control of improvisational working practices. One of these factors is a supportive organizational culture, and this specific area is dealt with in this paper. A particular focus is how the sample of organizations has attempted to identify and create supportive cultural conditions for improvisational work to take place. In order to bring clarity to the outcomes of this study, a matrix of the case study organizations is also offered, which segregates those organizations according to their cultural support for improvisation and apparent improvisation effectiveness. Some comment on the current difficulties in the Financial Services sector has also been included, as it could be argued that improvisation may have contributed to shortcomings in control processes by members of that sector.
\end{abstract}

Keywords: Improvisation, Culture, Financial Services

\section{Introduction}

Over the last ten years or so, evidence has emerged suggesting that more progressive organizations are moving away from a slavish adherence to agreed processes and procedures. Rather, they are exploring different, more radical ways of competing, which depend on allowing trusted and empowered employees to experiment with more creative and less predictable ways of achieving. This developing trend has been labeled organizational improvisation. The literature on organizational improvisation has matured, building on early philosophical ideals from Ryle (1979), and more organizationally-oriented work such as Weick's (1979) early insights into sensemaking. A number of later contributions have organized the evolving output (notably Cunha et al., 1999), and placed it in an appropriate managerial and theoretical context. As a result of this activity, organizational improvisation has progressed from being seen as a dysfunction resulting from poor planning (Quinn, 1980), to participating in, and becoming more recognized, within the lexicon of management theory (Leybourne, 2005). As our understanding of the antecedents, influencing factors, and outcomes of improvisation becomes more compre- hensive, it is time to focus on the supporting framework that allows successful improvisation to flourish in organizations. Arguably, one of the more influential of those preexisting conditions for effective organizational improvisation is a supportive organizational culture and climate.

This raises the question of how culture and climate support effective improvisational working practices. This paper will therefore examine various dimensions of organizational improvisation, and the way in which it is used within a range of organizations operating within a specific business sector, the intention being to isolate and analyze identifiable components of organizational culture and climate that may encourage or negate effective improvisation.

Although at the superficial level some practitioners perceive little difference between culture and climate, the academic definitions are quite distinct. Deal and Kennedy (1982) talk of culture in terms of: "the way things are done around here", although a more exact definition is "the collection of traditions, values, policies, beliefs, and attitudes that constitute a pervasive context for everything we do and think in an organization" (McLean \& Marshall, 1993). Organizational climate is a rather more ephemeral concept, and one which Mullins (1999: 810) 
suggests, when applied to organizations "can be said to relate to the prevailing atmosphere surrounding the organization, to the level of morale, and to the strength of feeling or belonging, care and goodwill among members". This review will deal with organizational culture first, examining it at both the sectoral and organizational level, before turning to the notion of climate.

The concept of culture has "...been borrowed from anthropology, where there is no consensus on its meaning” (Smircich, 1983: 339). Jelinek et al. (1983: 331) however suggest that culture is "...another word for social reality", and that it is "the shaper of human interaction and the outcome of it, continually created and recreated by people's ongoing interactions" (Jelinek et al., 1983: 331). Although this description of culture is by no means universally adopted, it does suggest that cultural norms are constantly changing. We are however interested in culture from an organizational and also from a sectoral viewpoint, and there have been a number of attempts to define culture in these contexts. Corporate or organizational culture is defined by Gordon (1991: 397) as "...an organization-specific system of widely shared assumptions and values that give rise to typical behavior patterns." Whipp et al. (1989: 565) suggested that "...the concept of culture, at the level of the firm, refers to the collection of beliefs, values and assumptions held by the members of an organization." Schein (1985) went further, defining three levels of cultural phenomena in organizations: at the surface level, behaviors; at the middle level, values; and at the deepest level, basic assumptions. He considered that the deeper basic assumptions were the essence of culture.

The emergence of organizational culture as an area of academic and managerial interest stems from a number of historic circumstances, including the changes in the nature of work brought about by flexible working and the breakdown of the "theory X" approach to management. As employees responded to organizational desire for "multi-skilled" capability, a desire has emerged to align or develop a "sense of belonging" to the organization. This has resulted in an increasing focus on organizational culture and climate, reflected in sets of differing values, norms, and beliefs, embedded in different structures and systems (Handy, 1993). It is also evident that different sets of these elements emerge at different loci, resulting in fragmented cultures.

The distinction between culture and climate can be a fragile one, and is often disputed. It is suggested that organizational climate promotes a psychological approach (Denison, 1990; Linstead, 2004), whilst neglecting the cultural and symbolic forms that inform culture. This indicates that climate can be short-lived, in that it reflects employees "feelings" towards an organization, which are prone to change (Schneider, 1983). Although both culture and climate are linked to the value system of organ- izational members (Rollinson \& Broadfield, 2002), the traditional view is that culture generates the values that are a component of how people act within an organization, whilst climate reflects the alignment between organizational and personal values. An alternative view, propounded by Denison (1996), is that the differences between culture and climate are minimal, and that the differences manifest themselves in terms of measurement.

Brookes \& Dawes (1999) consider the issue of merger or consolidation as a trigger for cultural change within organizations, suggesting that merger is an ideal opportunity to "...achieve a cultural change on a broader footing, in particular, embedding a much more customerdriven philosophy which could generate significant competitive advantage" (Brookes \& Dawes, 1999: 197). They also highlight the fact that they are espousing the "...human aspects of organization", or to apply another label, the socio-cultural systems which comprise organizations (Brookes \& Dawes, 1999: 195).

It is apparent that much environmental change has taken place in the management of the organization, and one of the ways that these adjustments are manifesting themselves is in a relaxation of processes and procedures, and a move towards allowing trusted and empowered employees to experiment with more creative, and less controlled, ways of achieving. Organizational improvisation is an example of one way that such creativity is being applied, although there are other established debates that contribute to the dismantling of organizational bureaucracy and the rise of autonomous working styles. Notably, the principles of responsible autonomy (Friedman, 1977), professional autonomy (Freidson, 2001; Faulconbridge \& Muzio, 2008), post-bureaucracy (Hecksher, 1994), and employee empowerment itself have all assisted in or argued the benefits of the relaxation of bureaucratic control.

However, responsible autonomy, where the aim is to integrate the workers to the goals of the organization by giving them independence and by encouraging them to adapt to possible changes at work and in work organization, is linked to manipulative aspects of employee "control" and to career hierarchies and progression, and to job security (Sturdy, Knights \& Willmott, 1992), whereas improvisation is enabled by "consent" to experiment with new ways of achieving organizational tasks and activities. Functional autonomy, which is defined by Friedson (1970: 53) as "the degree to which work can be carried out independently of organizational or medical supervision and can attract its own clientele independently" has elements that align usefully with improvisational work, but is essentially embedded in medical or professional, or client-based practice (Faulconbridge \& Muzio, 2008). Post-bureaucracy is the antithesis of the principles of bureaucratic organization (Hecksher, 1994), involving rationality and the allocation of defined and planned 
work. Although this mirrors the ethos of improvisation, the creative and intuitional components of improvisation (Moorman \& Miner, 1998a) add significantly to its effectiveness as an enabler of change, and as a lens for the analysis of cultural change.

There have been a number of comprehensive reviews of organizational improvisation (Cunha et al., 1999: Leybourne, 2006), much of which has evolved from Weick's (1979) work on sense-making, and Moorman and Miner's (1998a; 1998b) output that assists in identifying the early key constructs of creativity, intuition, and bricolage. Later work by Miner, Bassoff and Moorman (2001) posited adaptation, innovation, compression (in the temporal sense), and learning as additional constructs of improvisational activity within organizations. The development of management practices since the turn of the millennium has embraced a number of these constructs as important outcomes and antecedents of organizational performance, leading to an appreciation of improvisation as a lens for the analysis of organizational activity.

From a philosophical stance improvisation relates to how thoughts develop. Ryle (1979: 125) suggests that; "the vast majority of things that happen [are] unprecedented, unpredictable, and never to be repeated", and that "the things we say and do... cannot be completely pre-arranged". To a partly novel situation the response is necessarily partly novel, else it is not a response. His assertion is that however much an activity is planned, there will always be a novel set of circumstances to deal with, and that improvisation requires using resources that are to hand to resolve unforeseen circumstances. This assertion also resonates with the tenets of autonomous working, which is under adoption by modern organizations, and which is also the essence of bricolage (Lehner, 2000), which in turn is an essential component of improvisation (Moorman \& Miner, 1998a).

From the mid-1990s onwards much of the literature on improvisational work practices within organizations took this stance and applied it to organizational routines and processes. Some of the outcomes from these debates apply metaphors to explain the way improvisation is used, for example adopting and applying ideas from jazz performance (Barrett, 1998a \& 1998b; Eisenhardt, 1997; Hatch, 1998 \& 1999), and from improvisational theatre (Crossan, 1997; Kanter, 2002; Yanow, 2001). Later work used grounded theory approaches to consider the temporal aspects of improvisation, and particularly pressure to achieve complex tasks to a demanding or compressed timetable (Brown \& Eisenhardt, 1997; Moorman \& Miner, 1998a \& 1998b). This work is building the foundations to allow empirical research of a more positivist nature-for example: Akgun \& Lynn's (2002) work on the links between improvised new product development and speed-to-market. Latterly, consideration has also been given to the interactions between improvisation and learning (Chelariu et al., 2002, Miner et al., 2001), improvisation and entrepreneurial activity (Baker et al., 2003; Hmieleski \& Corbett, 2003) and the ways in which tacit knowledge (upon which intuition, and therefore improvisation, may draw) is acquired (Koskinen, Pihlanto \& Vanharanta, 2003), and the role of experience in the acquisition of tacit knowledge (Cooke-Davis, 2002). This is in turn feeding in to improvisation as a tool for strategic decision-making within turbulent environments (Velez-Castrillon, Vera \& Kachra, 2008).

The outcomes of this emerging literature base include an appreciation of the benefits and effectiveness of improvisational working practices, both as a tool and an appreciated skill for managers, and as a lens for the analysis of organizations. This stems from early work by Orlikowski and Hofman (1997), who suggest that organizational transformation (which is inherent in all modern organizations) is an ongoing improvisation enacted by organizational actors trying to make sense of and act coherently in the world, offering strong links to Weick's sense-making model. Mendonça, Cunha, Kaivo-oja and Ruff (2004: 213) suggest that "a crucial element for improvisation to occur is the existence of a 'safe' environment" which sees that the errors are not only inevitable, but also potential sources of learning, linking strongly with the requirement for a supportive organizational culture.

\section{Samples and Methods}

The study that underpins this research, and provides much of the primary data upon which the findings articulated in this paper have been based, was located in a sub-sector of the U.K. financial services sector. Six retail lending institutions, ranging from a major quoted bank, through building societies and ex-building societies (U. K.-based mutually-owned organizations originally formed specifically to supply housing finance), to smaller retail lending organizations, were used. This sample was chosen taking into account the relative populations of organizations in each of the sub-sectors, the required number of cases required to provide an opportunity to develop theory (Eisenhardt, 1989: 537; Stake, 1994: 237), and the need to include cases with differing characteristics, or polar types (Pettigrew, 1988).

The data collection and analysis involved a number of visits to each participant organization. The larger organizations received up to eight visits, with the smaller and more compactly organized organizations receiving from three to six visits. Over ninety employees and organizational stakeholders were interviewed, using a semi-structured interview framework derived from a rigorous operationalisation process, underpinned by the literature review. This resulted in the collection of in excess of 100 hours of highly relevant and focused interview data. Observational and secondary data, including project documentation, was also incorporated into this 
qualitative study. This data was analyzed, using the Huberman and Miles (1998) Interactive Data Analysis model as a guiding principle for data relevance, inclusion and reduction, and each of the six organizations was written up as a case study. Cross-case analysis was then undertaken, and themes, trends, and modes of operation were identified.

The use of computer aided qualitative data analysis software (CAQDAS) was considered, but was rejected, as there is a perceived danger that in adopting CAQDAS tools to analyze qualitative data, the researcher is forced to adapt to requirements imposed by the software (Woolgar, 1991; Lonkila, 1991). Lonkila suggests that such software programs "...could also be misused as purely rhetorical weapons to convince the readers or academic community of the scientific nature of ones research" (Lonkila, 1991: 46), and that it can “...prevent an interactive and easy movement between emerging conceptual structures and the data" (Lonkila, 1991: 49). Agar also sees a potentially destructive step in the process of analyzing qualitative data using software, notably, that there is a danger that a researcher may "...conduct an ethnography to maximize fit between the process and the available software" (Agar, 1991: 193). Fielding and Lee (1998: 68-84) also synthesise a number of disadvantages of CAQDAS, including accessibility and availability (Russell \& Gregory, 1993), the exaggeration of possible benefits (Wietzman \& Miles, 1995: 335), lack of closeness to the data (Agar, 1991: 185), and unintended consequences (Seidel, 1991: 109).

The study identified a number of processes, mechanisms and routines that the six organizations used (formally and informally) to develop and manage improvisational working practices. Often this improvisational activity is informal and surreptitious, and as such causes problems for the organizations, especially as they operate in a sector that is traditionally risk-averse (Brooks \& Dawes, 1999: 197; Trethowen \& Scullion, 1997: 62). The prime focus of this paper is however the movement away from standardized and documented processes and mechanisms, towards more improvisational modes of working, and how culture and climate within organizations may assist or hinder this shift.

\section{Case Study Findings}

Inevitably, the six case study organizations displayed varying levels of maturity, sophistication, and effectiveness in their understanding, control and management of improvisational working practices, and the culture that has emerged or been cultivated to support that activity. To some extent, this was linked to confidence in the ability of employees to improvise effectively, within a given framework that limited the extent of improvisational activity. The cultural norms and values of the organizations also significantly affected the way in which improvisa- tional working practices were used, or in some cases, abused. Each organization that contributed to the study is examined separately, the various issues examined, and a summarizing analysis made. A comparison across the six organizations will then be considered as a part of the wider conclusions.

\subsection{BigBank}

At BigBank, a major U.K.-based bank with over 77,000 employees, there was evidence of improvisational activity within a fragmented organizational culture, brought about by challenges in managing the merging of disparate acquisitions and merger partners. Notably, the management core of BigBank is formed from the senior managers of two merged banks with a centralized structure dominating, resulting in significant resistance from managers used to managing their own organizational domains.

One senior manager considered that it could possibly take a generation to remove the ingrained loyalties to one or other component bank, and suggested that "I could find you an 'Attilla the Hun' culture... and at the other end, a 'Mahatma Gandhi' culture. There is so much opportunity for individuals to build a culture how they want it to be in their area...”. The branch network has its own cultural problems. Branches often appear to take their cultural lead from the branch manager, and two of the branches visited had tight-knit, customer-focused teams, in each case led by a young manager who had built their own supportive branch culture. In direct contradiction to this approach, the I.T. and operations areas of the bank are traditionally acknowledged to have a more confrontational work environment, with greater personal accountability, a feeling that is noticeably less prevalent in other divisions of the organization. This may be compounded by the fact that, particularly within the systems areas of the bank, there is a strong focus and emphasis on delivery against the project timetable. It was also suggested that this delivery focus is present regardless of whether the need for the change has been superseded.

Within the merged bank, the part of the merged organization where managers were originally employed is referred to as "heritage". This term refers to the constituent part of the merged bank in which a person was originally employed, and there is an inference that employees still have loyalty to managers from their own heritage. It is however suggested that $70 \%$ of the junior staff employed by the merged organization have joined since 1995. These junior staff have little loyalty to either historic heritage within the enlarged bank. Another issue that has affected employees, particularly in the lending areas of BigBank, is the centralization of decision-making, and the removal of lending discretion from line managers within the branch network. This shift is familiar to employees from one half of the merged entity, but alien to employees from the other. Indeed, one Branch 
Manager in her 30's, who has been with one of the newly merged banks for her entire working life, suggested that prior to the 1995 merger, she "used to have an awful lot of discretion. It used to be a proper bank". Amongst more established middle managers, attitudes do appear to be linked to the working arrangements within the component bank where career progression was achieved.

The indicators are that although BigBank is moving forward in its re-focusing of the organization from a product to a customer focus, there is much work still to do. The change program run by the University of BigBank is however only experienced by about 200 middle managers each year, comprising less than $0.25 \%$ of the employee base, and the clash of heritage, which closely equates to historic culture within BigBank, is still causing concern.

There is significant support for improvisation within BigBank, with many operational areas, all change management respondents, and all project managers confirming that much of their work is improvised. The virtual university disseminates research from, amongst other sources, the Cranfield School of Management on informal pockets of best practice, which is seen by BigBank as closely linked to improvisation. There is evidence that although the bank has formal structures and processes, another set of activities achieves much of the real progress. These activities are based on informal networks and relationships, and they appear to operate outside of the procedures and guidelines documented by the bank.

There is recognition within BigBank that this can assist in managing change. One manager linked this to the organizational climate of the bank, arguing:

"I think the climate... is more one of, if you are working within the broad framework of... management and you can find a better way of achieving the goal more effectively, then I think you have got the freedom to [do that]. Therefore, improvise or innovate"
This attitude indicates strong support for improvisational work routines. Also, evidence from within the organization underpins the fact that at many levels and functional specializations, improvisation is supported.

During the discussions within BigBank many instances of these informal routines and improvisational activities were identified. A senior manager in the Management Development area of the bank suggested that:

"Actually most of the work that does happen in the organization is done through informal structures, loose collaborations of people who have similar views or initiatives... Actually you just get on the phone and make something happen informally, which fits with the idea of improvisation for me".

Improvisation is therefore recognized as a valid, and in some areas an essential, component in change. However, there is evidence that the opportunity to improvise is being deliberately removed from branch systems and processes, which may run counter to BigBank's intention to focus on customers, many of whom use a branch as their principal channel to access products offered by the bank. Table 1 displays the cultural and improvisational attributes of BigBank.

\subsection{MutualCo}

MutualCo is one of the few surviving Mutually-owned mortgage lending organizations in U.K., with a workforce of approximately 1300. It devotes significant time and energy to the development of its employees, and a recent staff satisfaction survey showed that matters were improving. Senior managers within the society are taking more interest in the skills and development of employees. Managers suggest that the focus has moved from delivery of benefits, to a more behavioral focus, where training and the effect of changes on a developing workforce is appreciated.

Table 1. Cultural and improvisational attributes of BigBank

\begin{tabular}{|c|c|}
\hline \multicolumn{2}{|l|}{ BigBank - Cultural and Improvisational Attributes } \\
\hline Culture - Positive Attributes & Culture - Negative Attributes \\
\hline $\begin{array}{l}\text { - } \quad \text { Strong linkages between projects, H.R., and training } \\
\text { - } \quad \text { Dedicated area change managers monitoring impact of } \\
\text { change on staff } \\
\text { - } \quad \text { Dedicated department to communicate major change } \\
\text { - } \quad \text { Use of training maps for career development } \\
\text { - } \quad \text { Attempts to measure behavioral change }\end{array}$ & $\begin{array}{ll}\text { - } & \text { Excessive use of political influence by senior managers } \\
\text { - } & \text { Project procedures and methods have little coverage of peo- } \\
\text { ple/cultural issues } \\
\text { - } \quad \text { Many layers of authority/hierarchy } \\
\text { - } \quad \text { Cuck of time for self-training } \\
\text { operational areas causing entrenched resistance }\end{array}$ \\
\hline Improvisation - Positive Attributes & Improvisation - Negative Attributes \\
\hline $\begin{array}{ll}\text { - } & \text { Support for improvisation implicit within the organization } \\
\text { - } & \text { Training on aspects of improvisation } \\
\text { - } & \text { Informal networks to assist with improvisation } \\
\text { - } & \text { Improvisation accepted as contributing to project-managed } \\
\text { change }\end{array}$ & $\begin{array}{l}\text { - } \quad \text { Rigidity in customer-facing procedures negates improvisation } \\
\text { Perception that senior managers are deeply entrenched in } \\
\text { traditional banking mentality }\end{array}$ \\
\hline
\end{tabular}


Recently there has been a more focused approach towards culture and employee behaviors. However, the Group I.T. Manager attempted to put this into perspective, suggesting that:

"the current man [new chief executive] is trying to change the culture of MutualCo, and I think he is going to have a hard job... the words that come out are, he wants us to work, but he wants us to be happy, and he wants us to have fun. They are light words, and everybody wants to be happy and have fun, but it is no good when you have an avalanche coming down on top of you with work loads all the time, and you work the weekend, and you work nights. If they want people to be happy in their work, they have got to stop putting people under so much pressure, and try to reward them in the best way that they can."

At a less influential level, a junior Customer Services Helpdesk Operator reinforced this view, saying:

"When I first started with the society, I thought they were a very caring society and they were interested in your thoughts. We seemed to drift away from that about 2 years ago, although now we seem to be getting back into it. Before, it was very much, you either do these targets, or maybe the job that you are doing isn't suitable for you anymore."

These comments point to a dual standard in the society, with the rhetoric leaning towards a focus on employee relations, with activity directed towards improving skills and behaviors. However, the reality is that there is still an emphasis on progress, delivery, and the achievement of targets.

Communication is also recognized as a problem, especially in the branch network. One employee pointed out "Once you start going outside of Head Office, then I think that perhaps the communication is not that strong". There is however evidence that the situation is improving, and the society intranet and E-mail is acknowledged to be assisting in this area. Under the new senior management team, managers particularly talk about leaving the blame culture behind, moving away from the risk-averse culture of the mid 1990s, and a "work hard-play hard" environment.

One manager recognized that within the projects and I.T. area, attempts were being made to address some of these cultural issues, saying "they are trying to move from a blame culture to one of, OK, you can make a mistake, and that is learnful... fault would be apportioned, but not in a negative way...”. It is however apparent that the culture of MutualCo is fragmented. This is resulting in at least one department attempting to address its cultural shortcomings independently. There is also a widely held view that the move to a new, modern Head Office building will remedy cultural shortcomings within the organization, and assist with healing cultural fragmentation. This is however unlikely to happen without considerable complementary activity.

The positive and negative cultural attributes of MutualCo are displayed in Table 2. It is apparent from these attributes that much effort is being directed towards the development of employees, and the creation of a sympathetic environment to allow them to thrive and produce results for the society. However, it appears that at the Executive Director level, pressure is still applied to employees to produce improvements in effort, performance, and output, without sufficient attention to the social and behavioral issues that impinge upon such improvement activity.

MutualCo has an approach to the creation and planning of change that is moderately rigid, using tools and techniques drawn from methodologies such as PRINCE ${ }^{1}$. There is however recognition at all levels within the managerial hierarchy that forms of improvisation are used, but the degree is disputed. The Head of I.T. describes this type of activity in terms of "work-arounds"

Table 2. Cultural and improvisational attributes of MutualCo

\begin{tabular}{|c|c|}
\hline \multicolumn{2}{|l|}{ MutualCo -Cultural and Improvisational Attributes } \\
\hline Culture - Positive Attributes & Culture - Negative Attributes \\
\hline $\begin{array}{l}\text { - } \quad \text { New senior management emphasis on people aspects of the } \\
\text { organization } \\
\text { - } \quad \text { Starting to manage tacit knowledge } \\
\text { - } \quad \text { New emphasis on retraining and stimulating staff } \\
\text { - } \quad \text { Decision-making devolved to lower levels }\end{array}$ & $\begin{array}{l}\text { - } \quad \text { Geographical scattering of departments hampering communication } \\
\text { - } \quad \text { Major growth has led to focus on product development projects } \\
\text { rather than Behavioral Projects } \\
\text { - } \quad \text { Head office relocation caused skills losses } \\
\text { - } \quad \text { Project management standards do not include people/cultural issues } \\
\text { Problems with communication, especially to branch network/staff }\end{array}$ \\
\hline Improvisation - Positive Attributes & Improvisation - Negative Attributes \\
\hline $\begin{array}{l}\text { - Willingness to accept improvisation as an accelerator of } \\
\text { change } \\
\text { - } \\
\text { Program/project managers admit to the regular use of im- } \\
\text { provisation }\end{array}$ & $\begin{array}{ll}\text { - } & \text { Conflict with internal audit department } \\
\text { - } & \text { Risk aversion negatively influences ability to improvise } \\
\text { - } & \text { Pressure to deliver may encourage reckless improvisation }\end{array}$ \\
\hline
\end{tabular}

\footnotetext{
'PRINCE’ (Projects IN a Controlled Environment) and PRINCE2’ are project management methodologies widely used in the UK Public Sector.
} 
and "management of the issues". Middle managers articulate improvisational processes more strongly, suggesting that "I improvise to get things done", "I will get it done any way I can", and "you couldn't get a project 'live' without improvisation”. The group I.T. manager reinforced this view, suggesting:

"If our chief exec wants something done, it is going to happen, and if he wants it done in a month, we will say, I doubt if we can do it. We will try for it, but one of the first things that goes is following all the rules and regulations, crossing the ' $t$ 's, dotting the ' $i$ 's, doing the documentation, that goes out."

It appears that this is accepted within the organization, and there is clear evidence of high levels of improvisational activity within MutualCo. There is however a conflict between this attitude and the auditing of processes and project plans, and project managers complain of pressure to deliver projects quickly, and the lack of involvement of internal auditors in project planning and project progress meetings.

It appears that, notwithstanding a real sense of risk aversion within the organization embedded by 150 years of tradition, and a stable market for the single loan product offered for much of that time, areas of MutualCo are changing. As a result of the relative lack of development historically, the change that is now being achieved is happening in spite of the many problems that exist within the organization. Managers using improvisational practices appear to be the catalyst for such change. The positive and negative attributes relating to culture and improvisation within MutualCo are displayed in Table 2.

\subsection{ExSociety}

ExSociety was a mutually-owned mortgage lending organization, but is now part of a very large banking and finance Plc. As an organization, it appears to have a well developed and well communicated vision and values, widely adopted and championed across the organization. The organizational culture of ExSociety is well developed, coherent, and appears to be homogeneous and respected across the organization. Cultural norms are reinforced by the recognition and provision of single status facilities, and are built around two key messages; "doing the right thing”, and a continuing focus on customer excellence. The adoption of customer satisfaction as a key performance indicator within ExSociety has had a significant effect the evolving culture and on performance since its adoption in the late 1990s.

Initial impressions of ExSociety are favorable, with harmonization initiatives and the inclusion of employee issues having a positive effect on employee morale, commitment, and enthusiasm. There is strong evidence of adoption of the vision and values, which include employee development, at all levels within the organization. Indeed, in discussing the values of the organization, one manager from the compliance and internal audit area who had been employed with ExSociety for about a year stated:

"Something I have not come across before in a company is, it is almost taken to heart by all the staff, and they recognize it, and they understand it, and they effectively live by it. They try to 'do the right thing',".

There have been various descriptions of the culture of ExSociety, including entrepreneurial, changing, innovative, people oriented, welcoming, open, and honest, friendly, and caring. These all appear to be positive attributes, and the evidence collected within and around ExSociety is generally supportive of and consistent with these labels, notwithstanding the amount of change that has allegedly taken place in the last decade. ExSociety also shares knowledge. If "best practice" is identified by a work team, forums are used to disseminate such information throughout the organization. Identification of and exploitation of these pockets of best practice that develop within ExSociety is seen as a key activity in the improvement of working practices.

Improvisation is accepted as a desirable skill across the whole of ExSociety. One member of the branch staff, when asked whether she had the opportunity to improvise, said "ExSociety encourage taking ownership of everything. I think that is a good thing really, because it gives people confidence to think, 'well, if there is a problem, how do I solve it', rather than passing it on, and thinking, "well, this is not really to do with me'”. This statement links neatly with the concept of "ownership" that is enshrined in the corporate values of ExSociety. Also, there is a very strong alignment between these values and the attitudes of employees, and improvisation is encouraged if it contributes to the delivery of excellence to the customer.

Discussions with the Strategic Change Manager also revealed strong support for improvisational activity, which he sees as the way in which most work is managed and achieved. A Compliance Manager did however point out that, given the volume of regulation within the sector, it was important to set boundaries, and that those boundaries would have to be "embedded in training". This suggests a dualist view. Improvisation is used extensively to allow customer service employees to deliver customer excellence. The evidence does however indicate that some areas of change would benefit from a less rigorous approach, provided that a framework was defined for such improvisation. Within ExSociety managers have tended to identify and link improvisation with other initiatives such as continuous improvement, which provide the framework within which employees can be encouraged to improvise in order to enhance the delivery of job outputs. There is also an acceptance that the desires of the current parent organization may inhibit improvisation. 
Table 3. Cultural and improvisational attributes of ExSociety

\begin{tabular}{|c|c|}
\hline \multicolumn{2}{|l|}{ ExSociety - Cultural and Improvisational Attributes } \\
\hline Culture - Positive Attributes & $\underline{\text { Culture - Negative Attributes }}$ \\
\hline $\begin{array}{ll}\text { - } & \text { Vision and values that are inclusive of employees } \\
\text { - } & \text { Open communication at all levels } \\
\text { - } & \text { Lack of status badges } \\
\text { - } & \text { Investment in employees } \\
\text { - } & \text { Relative lack of blame apportionment within the mechanisms } \\
\text { of change }\end{array}$ & $\begin{array}{l}\text { - } \quad \text { Some evidence of minor political activity linked } \\
\text { with the parent } \\
\text { - A perceived need by some managers that more } \\
\text { emphasis is needed on knowledge and behaviors }\end{array}$ \\
\hline Improvisation - Positive Attributes & Improvisation - Negative Attributes \\
\hline $\begin{array}{ll}\text { - } & \text { Improvisation recognized as contributing towards speed and } \\
\text { innovation within the organization } \\
\text { - } & \text { Senior management support for improvisational activity } \\
\text { - } & \text { Audit and Compliance support, within agreed boundaries }\end{array}$ & 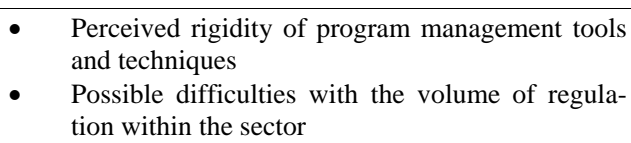 \\
\hline
\end{tabular}

Table 3 displays the key positive and negative attributes of ExSociety that impinge upon its culture, and upon the ability of the organization to improvise within its change initiatives. However, the apparently open and innovative culture of this organization should assist in setting a framework within which improvisation can be used to support such change, and there appears to be a keen desire to achieve this within ExSociety.

\subsection{FinanceCo}

This company is a relatively autonomous Finance subsidiary of a major U.K. bank. There is an admission from FinanceCo employees at all levels that throughout the 1990s the overarching focus was on developing and nurturing an aggressive sales culture. This is changing with integration with the parent, with the Governor of the parent bank stating "we reinforce our ability to fulfill the professional and personal aspirations of our staff with a learning culture which permeates the whole of our business. Everyone benefits from the infectious enthusiasm this culture breeds...". However, it is acknowledged that much work is needed to meet the expectations of that statement, particularly within FinanceCo, where a politically oriented and sales driven culture has prevailed.

One manager confirmed that training in the behavioral aspects of managing is lacking, saying "I don't think anything specific is being done on those kinds of soft skills that are required", even though "they are probably the key parts for the manager". This contrasts with the opinion of his manager, who suggested when talking about the behavioral aspects of managing teams that there will be "tasks that actually make inference to the fact that you should be doing that [managing team behaviors]". The importance of addressing such skills has already been considered, and evidence reinforces and supports those findings.

The learning culture espoused by the senior executives of the parent bank is now beginning to diffuse throughout FinanceCo, and a new director, part of whose role is to manage this culture change, has been appointed to the H.R. area of the newly integrated organization. Initiatives are currently being considered to access the considerable body of industry-specific knowledge that has built up within FinanceCo over many years, and to make it available on a wider basis. However, this work is in the very early stages of development, and may run counter to the sales and performance related historic culture.

The integration of FinanceCo into the parent bank has been rationalized on the basis of "sharing best work practices, harmonizing" although one manager suggested that "the way it was sold was... that it would be working together, very collaborative, and I think initially that did not happen. It was very much, 'we are the parent, you are the sibling'... and we are in charge." It is certainly apparent from responses across all parts of the organization that the parent bank has taken control, and that it was always their intention to limit what they perceived as cost and authority excesses within FinanceCo.

Rather naturally, the culture within the newly organized set of businesses is fragmented, and appears to be moving from a power culture towards a composite of role culture and task culture (Handy, 1993: 183-192). Culturally, FinanceCo is seen as being more sales and customer-oriented than the parent bank, and part of the rationale for the integration of FinanceCo into the parent bank is to exercise more control over these management shortcomings. The company is evolving from a traditional hierarchical structure, and has attempted to move from this model to a more reactive and flexible way of working. In order to achieve this, the organization is attempting to embrace less structured processes and mechanisms within those areas of the business where such practices are appropriate. In reality, this desire seems to be stimulating more improvisational working within the sales-oriented areas, and also in those areas where creativity and free thinking can contribute to perceived improvement.

It is however apparent that there are areas that are ac- 
tively resisting a move towards more improvisational practices. Many areas of FinanceCo are becoming more rigid in their working practices as a result of the increasing influence of the parent bank, which is recognized as having a long history of cautious growth, and an aversion to risk taking. This caution is manifesting itself in the imposition of controls on areas of FinanceCo. Specifically, the I.T. area and the collections and litigation areas operate under service level agreements with their internal client departments, and these agreements specify processes and mechanisms that are mandatory. This restrains the ability and inclination of employees in those areas to improvise, notwithstanding the desire of the parent bank to learn from the allegedly more entrepreneural and improvisational practices of FinanceCo.

There is however a feeling within FinanceCo that improvisational practices will assist in the future development of the organization. Within the lending areas of FinanceCo, the management interest is on improvisation in order to win business and to meet customer expectations. The management of risk is equally important, but the organizational focus within FinanceCo is on ensuring that loans are profitable, and that flexibility exists to satisfy customer demands. One manager within Group Training and Development suggested that some people felt more secure within a comfort zone that acted as a framework for their actions, whereas others were happy with improvisational techniques. He was also of the opinion that it was up to a manager to manage these preferences within his team. However, the data suggests that FinanceCo respondents have mixed views about improvisational work practices, and evidence indicates that there is doubt about their use. Specifically, the PRINCE-based routines imposed on the I. T. area of the organization impart a rigour that negates improvisation. It is however apparent that some managers still improvise to achieve tasks, and that there is greater use of improvisation within customer service areas.

The key positive and negative attributes relating to cultural aspects, and also to the use of improvisation within FinanceCo are detailed in Table 4. It is however apparent that improvisation is used extensively across the various functional specializations within the organization, albeit that more rigidity and structure appears to exist within the I.T. development and support areas of the business.

\subsection{NewCo}

NewCo is a small lending organization, with a staff of around 150, delivering loan products via a call centre, an internet accessed applications systems, and a small broker network. The overarching philosophy within NewCo is the importance of the culture of the organization, and the emphasis that is placed upon staff development, training, and the social and behavioral aspects of working. The atmosphere within the offices is one of quiet professionalism, but with no overbearing sense of authority or discipline. Workers are smart, and senior employees are mainly dressed in suits, whilst more junior staff tend to be dressed more casually. NewCo has a well-defined and well-publicized vision and values, which is prominently displayed in most open areas and manager's offices.

Employees work in teams, and team members are paired up with a "buddy"-new staff with an experienced one in order to share expertise and learning. This system is used across most areas of the organization. The senior management is very visible, and informal contact with management is a normal occurrence. Directors and managers are addressed and referred to on a first name basis, and NewCo organizes regular social events, which senior managers attend.

HR development issues are well defined, with incentives, and mechanisms for assessing performance against agreed targets and core skills. This focus on staff development is a major influence in shaping the culture of $\mathrm{NewCo}$, and it links closely with the aforementioned vision and values. In addition, the organization works hard to build an atmosphere of cooperation and caring amongst staff at all levels, using a combination of suggestion schemes, staff incentives, targets and rewards, and social

Table 4. Cultural and improvisational attributes of FinanceCo

\begin{tabular}{|c|c|}
\hline \multicolumn{2}{|l|}{ FinanceCo - Cultural and Improvisational Attributes } \\
\hline Culture - Positive Attributes & Culture - Negative Attributes \\
\hline $\begin{array}{ll}\text { - } & \text { Willingness to recognize pockets of internal expertise } \\
\text { - } & \text { Curbing of cost excesses } \\
\text { - } & \text { Appointment of new senior H.R. executive } \\
& \text { Parent-imposed move to a learning culture }\end{array}$ & $\begin{array}{l}\text { - Limited training activity in behavioral aspects of } \\
\text { managing } \\
\text { Evidence of weaknesses in socio-behavioral skills } \\
\text { training }\end{array}$ \\
\hline$\underline{\underline{\text { Improv }}}$ & $\underline{\text { Improvisation - Negative Attributes }}$ \\
\hline $\begin{array}{ll}\text { - } & \text { Allows quick responses to external changes within } \\
\text { - } & \text { Allows flexibility in structuring lending products } \\
\text { - } & \text { Allows employees to meet customer expectations } \\
\text { - } & \text { Support from Group Internal Audit }\end{array}$ & $\begin{array}{l}\text { - Loss of control over processes by senior manage- } \\
\text { ment } \\
\text { - } \quad \text { Not a substitute for poor planning and execution } \\
\text { Less accepted within the I.T. area }\end{array}$ \\
\hline
\end{tabular}


Table 5. Cultural and improvisational attributes of NewCo

\begin{tabular}{llll}
\hline NewCo - Cultural and Improvisational Attributes & & Culture - Negative Attributes \\
\hline Culture - Positive Attributes & Strong focus on quality of staff & Speed of growth may adversely affect current culture \\
\hline - $\quad$ Strong focus on development of staff & Effect of new parent company not yet known, lead- \\
ing to uncertainty
\end{tabular}

events. Visual evidence of this abounds within NewCo. Staff at all levels appreciate this activity, and numerous interview respondents suggested that NewCo was not only the best organization they had worked for, but also that they were well paid, and that good work was encouraged, recognized, and rewarded. Introducers and suppliers have also benefited from this approach, with a NewCo "open day" and golf tournament called "One Great Day”, indicating the confidence of the organization.

Currently, NewCo is of a size where employees are aware of each other and their different skill sets, although as the organization grows, this will cease to be the case. Idea generators have differing levels and mixes of skills, and utilize varying ways of planning and executing these process changes. Communication is also seen as vital across $\mathrm{NewCo}$, and there are effective formal and informal networks of communication in operation within the business. The Marketing Director of NewCo stated "communications is something we work very, very hard at..." and junior staff admit that the communication at NewCo is "much better" than previous employers. This focus on communication is assisting in the relatively effective management within the organization.

Within NewCo innovative thinking, rapid decisionmaking, and a speedy transition from idea generation to implementation are encouraged, and there was an attempt to reflect this in the way in which the organization developed in its first years of operation. As the organization has grown, a degree of formality has been introduced, but the senior management encourages innovation by staff, together with creativity, which is one of the important components of improvisation. This encouragement comes from a willingness to allow staff the freedom to try new ways of achieving work tasks, and informal networks within the organization act as conduits for the dissemination of new working practices. There is also an informal forum to discuss these issues, and a mechanism, albeit also informal, to feed emerging best practice back into new written procedures.

Improvisational work practices are encouraged by de- liberately not surrounding employees with documented routines and formalized sets of expectations about how work is to be carried out. Team members and their managers are allowed to decide on work flows, responsibilities, and job design, and the sharing of pockets of best practice that emerge from this loose structure is encouraged. A set of limits to the framework within which work can be improvised is encapsulated into induction training, and is also passed on to new employees via the "buddying” system, which also provides an element of informal control.

There are many examples of improvisation within the data. Most notably, the whole area of user-led change to internal processes could be said to involve improvisation, as the majority of these initiatives appear to arise as a result of team members undertaking tasks or meeting customer expectations outside of formal organizational procedures. If these initiatives are proven to work, they are informally adopted, and disseminated across the organization using formal and informal employee networks. Ultimately, they are formally adopted into organizational routines. There is evidence that this improvisational activity is seen by NewCo as " $a$ way of staying ahead of the competition" by compressing the time needed to react to market signals.

It can be seen that improvisation is encouraged across the organization. However, NewCo is growing quickly, and there is evidence that although controls have evolved, they are relaxed in favor of a more improvisational style of working when problems arise or when systems, processes, or routines need to be altered quickly. The positive and negative attributes relating to culture and to improvisational activity within NewCo are noted in Table 5. There is however considerable evidence to suggest that improvisation has been accepted as an important component of work carried out within $\mathrm{NewCo}$, and that senior managers within the organization see strong links between improvisation, innovation, and the ability to meet customer requirements. 


\subsection{DivestCo}

This organization is a long-established consumer finance and loan company, with an extensive branch network, which has gone through much change, and now needs to stabilize. One analyst from the strategy team talked of "building a robust operational platform from which to pursue strategies”, and the Senior Manager-Organizational Development, who is responsible for people and excellence issues, talked of the need for " $a$ period of stability and consolidation". However, currently DivestCo, having divested of its core business, is attempting to survey the opportunities that exist within its chosen sector, in order to make choices as to its future direction. Concurrently with this activity, work is progressing to develop a set of organizational values that will assist in enabling the company to achieve its aims within such a future strategy. This activity appears somewhat premature, as the required values are likely to differ according to the chosen direction. There is also evidence of acceptance within DivestCo that, regardless of the chosen strategy, important issues to address in the future will revolve around employee behaviors and the culture of the organization.

Notwithstanding this need to address cultural issues, DivestCo has already moved some way towards a more open and blame free culture. It is also apparent that different cultures prevail in different parts of the organization, with a macho, performance and volume-driven culture within the sales and branch departments, and evidence of a more intimate, almost paternal, yet politicized culture within most parts of the head office. The Senior Manager-Organizational Development also said "we pride ourselves on having a can-do culture", although there are perceived frictions between such a statement and freedom from blame within the culture of the organization. It appears that there are a number of contradictions within the data as it relates to the culture of DivestCo. There is no doubt that the culture is not homogeneous, and this is demonstrated by the sales-based, performance-driven culture of the branch employees, contrast with cursory attempts to generate a more sympathetic and people-centered culture within parts of head office. Additionally, this divergence is complicated by an outwardly distant team of senior managers, who do not visibly interact with other employees.

There is a natural tension between the rigidity and robustness of some processes imposed upon DivestCo by its parent, and the desire to improvise in order to shorten delivery times for change initiatives. This has resulted in a desire to improvise, which is tempered by adopted standards and procedures. At various levels within the organization, the recognition of improvisation as a positive factor is accepted, with the Head of H.R. saying "it probably doesn't happen enough...", and the Strategic Change Manager saying "I do it all the time." It is how- ever evident that some functional areas are less inclined to improvise, as evidenced by the Finance Manager, who stated "improvisation sounds a bit scary to me, I have to say, from an accountants point of view".

Evidence supports the use of improvisation within DivestCo, but it is apparent that there are considerable differences of opinion as to use. The rhetoric surrounding improvisation relates to flexibility, serving the customer, and being innovative in the way lending can be structured. However, the reality seems to be closer to achieving the "can do" philosophy by doing whatever is necessary to deliver agreed outputs, regardless of the current need for them. Against this background, there is an appreciation within the company of the positive effects of improvisation. Notwithstanding this appreciation, with the current exercise to develop a new vision and values for the organization, together with the cultural changes that may be required in their adoption, there is a view that improvisational tendencies may need to be suppressed in the short term. It is however recognized that controlled improvisation is good for the organization, as it contributes to the generation of ideas, to the creation of new and innovative products, and to initiatives that will ultimately lead to the development and success of DivestCo.

There is strong evidence of the use of improvisational processes within DivestCo, and there is a perception that a key element surrounding improvisational processes is the control of risk. DivestCo addresses this link between risk and control formally, running workshops on balancing risk with control. One manager suggested that about fifty percent of his work was improvised, and a number of respondents saw improvisation as an extension of the continuous improvement process that is used to manage more informal change. Table 6 summarizes the positive and negative attributes relating to culture and to improvised routines within DivestCo.

\section{Comparative Findings and Discussions}

The desire to manage organizational culture is at the forefront of many managers' aspirations (Ogbonna \& Harris, 1998: 273). Organizational culture is also an important component in the management of strategic change. Pant and Lachman (1998: 196) suggest that strategies contain implicit values that need to align with the values of the organization. ExSociety and NewCo are comfortable with the values implicit in their organizational culture, and attempt to ensure that change initiatives are coordinated with those values. Organizational culture does however embrace a wider set of components. Schein (1985) identified three levels of culture "surface manifestations", which are behavior patterns that can be seen and heard; the aforementioned "values", which are located below surface manifestations, and underpin them, and "basic assumptions", those things that individuals 
hold about the organization and how it functions. These assumptions can be difficult to access and identify. He suggests that culture consists of basic assumptions, and that surface manifestations and values are generated by and support such assumptions. Each is however valid in considering culture within organizations, and will be applied to the cases in turn.

The surface manifestations of the case study organizations differ greatly. BigBank has many divisions, and over 2500 branches and other locations, with limited cultural homogeneity across them, notwithstanding an attempt to create this. MutualCo attempts to offer a consistent message across branch premises, and is hopeful that its new Head Office building will allow it to create a homogeneous culture. ExSociety also has a positive Head Office image, and there is evidence that it also labors to make the culture inclusive of the branch network. FinanceCo and DivestCo project a fragmented set of surface manifestations, with significant structural problems, and NewCo has by far the most consistent set of surface manifestations, being a small organization located in a single building.

Each organization has a documented organizational vision, and a set of values that underpin the vision. In $E x$ Society and NewCo, employees have adopted the values of the organization very positively. DivestCo was developing a new vision and a new set of organizational values during the period that data for this study was being collected. There was however an assumption within the organization that it would "end up with more old DivestCo values". In BigBank, there is a contradiction between the vision and values, which articulate matters relating to customer relationships and products, and the over-riding organizational focus of the bank, which is “enhancing shareholder value”. In MutualCo and FinanceCo, there appears to be little connection between the attitudes of the employees and the organizational vision and values, other than a commitment to mutuality within MutualCo. This however appears to be driven by a desire to survive as an independent organization, rather than an articulation of organizational values to be adop- ted by employees.

The basic assumptions within Schein's (1985) three level schema of organizational culture are more difficult to assess, notwithstanding the fact that Schein sees them as the essence of organizational culture. Two important aspects of such assumptions are an organization's relationship with its environment, and the way in which the organization perceives itself. These aspects can be considered in the context of the persona that the organization projects to its stakeholders. This can be drawn from a synthesis of data contained in organizational mission statements and similar artefacts, albeit that this persona can fragment across different parts of an organization. A summary of the three levels of culture for each case study organization is displayed in Table 7.

Table 6. Cultural and improvisational attributes of DivestCo

\begin{tabular}{|c|c|}
\hline \multicolumn{2}{|l|}{ DivestCo - Cultural and Improvisational Attributes } \\
\hline Culture - Positive Attributes & Culture - Negative Attributes \\
\hline $\begin{array}{l}\text { - } \quad \text { Activity to change cultural norms } \\
\text { - } \quad \text { Attempts to move away from a "blame" culture }\end{array}$ & $\begin{array}{l}\text { - } \quad \text { Non-visibility of senior managers } \\
\text { Lack of effective communication within specific areas } \\
\text { of the business }\end{array}$ \\
\hline Improvisation - Positive Attributes & Improvisation - Negative Attributes \\
\hline $\begin{array}{l}\text { - } \\
\text { Recognition that improvisation is effective in certain } \\
\text { - } \quad \text { An admission that many people use improvisation } \\
\text { - } \quad \text { A desire to improve improvisation skills } \\
\text { - } \quad \text { Formalization of some areas relating to improvisation. } \\
\text { - Workshops to address the link between risk and control }\end{array}$ & $\begin{array}{l}\text { - Risk aversion within the organization } \\
\text { - Tensions between improvisation and the need to ad- } \\
\text { dress regulatory constraints }\end{array}$ \\
\hline
\end{tabular}

Table 7. Assessment of cultural levels

\begin{tabular}{cccc}
\hline & \multicolumn{2}{c}{ Assessment of Cultural Levels } & \\
Organization & Surface Manifestations & Values & Basic Assumptions \\
BigBank & Fragmented & Contradictory & Enhancing Shareholder Value \\
MutualCo & Fragmented but Improving & Weak but Focused & Customer Value through Mutuality \\
ExSociety & Homogeneous and Positive & Strong & Customer Excellence \\
FinanceCo & Fragmented and Troubled & Weak & Proactive Product Innovation \\
NewCo & Homogeneous and Very Positive & Strong & Employee and Customer Focus \\
DivestCo & Fragmented and Uncertain & Developing & Growing Profitable Businesses \\
\hline
\end{tabular}


Many of the practices and mechanisms used to manage change in the case study organizations conform to the "informally formal" description in Bacon et al. (1996: 95). A degree of formality is provided by documented standards and procedures, and informality is evidenced by the relative freedom of managers to interpret the execution phase of change projects as they wish, including the use of improvisation. This seems to point again to the need for hybrid managers. Perhaps patterns of practice which exhibit an informal formality may provide a key to resolving the tension between the need for systematic practices and consistency on one hand, and intuitive organic practices that nurture innovation and flexibility on the other.

It would therefore assist organizations to ensure that employees have the skills to work in an informally formal way, and so contribute positively. In order to recruit and develop such skills, the case study organizations are attempting to develop or acquire employees with suitable skill-based and socio-behavioral profiles, and support those people to grow with the organization, and to change as it changes. ExSociety and NewCo are achieving the most success in this area, and BigBank and DivestCo are improving. FinanceCo is poor, but could improve as a circumstance of integration into its parent, and MutualCo appears to be saddled with a number of long-serving middle managers who are holding this process back.

Evidence within this study indicates that ExSociety and $\mathrm{NewCo}$, who devote much time and effort to the recruitment and development of employees with flexible skillsets and attitudes, achieve change better. Additionally, respondents opinions and secondary data from project plans and post implementation reviews strongly suggests that these two organizations have enthusiastically adopted team-based project structures to implement change, and devote considerable time and resources to the effective use of team-based processes and mechanisms. This is important, as ideally within change activities, disparate groups of third-party and permanent employees are melded into effectively functioning project teams, capable of delivering the required change. There is a strong trend in the data towards a link between socio-behavioral and cultural factors, and the satisfactory performance of change initiatives. The superior performance of ExSociety and NewCo in this area has already been discussed. The relatively poor performance of FinanceCo, and the poor but improving performance of MutualCo, tend to reinforce this linkage, given that FinanceCo is weak in socio-behavioral areas, and MutualCo is improving under its new, more people-centered developing culture.

There is however overwhelming evidence of extensive use and acceptance of improvisation in the management of change within the respondent organizations. Some of this activity is conscious, and some emerges because of circumstances. Chelariu et al. (2002: 141) suggest that this organizational activity is “... a reflection of the pressures of an environment characterized by unprecedented fast change." Stacey (1996) maintains that these environmental conditions are uncertainty, complexity (described in terms of interdependent environments), and dynamism (described in terms of short-lived opportunities and threats to survival). U.K. retail financial service is such an environment. Improvisation assists in dealing with this volume of change, and BigBank senior managers and project managers are keen exponents. MutualCo managers suggest that they could not operate without improvising. ExSociety have the most rigidly applied project standards and procedures, but at senior levels there is a belief that there is insufficient improvisation, and that this is stifling innovation. Interestingly, there is less improvisation by project managers within ExSociety than in any other case study organization, with the exception of FinanceCo, which produced the least evidence of improvisation. NewCo uses such techniques across the organization, and is also developing effective mechanisms to capture the emerging best practice that accrues. Evidence from DivestCo indicates that there is a willingness to improvise, but this is bounded by the memory of major failures in the mid 1990s, where an element of blame was attached to insufficiently rigid processes. It is apparent from the data that there are significant differences across the organizations, and across levels of seniority within those organizations. Some improvisation is also surreptitious, avoiding accountability and the scrutiny of senior managers.

Given such environments, it is understandable that the case study organizations may wish to use improvisational practices. There are however doubts as to its effectiveness, and none of the organizations are able to support empirically an assertion demonstrating that improvisation aids the management of strategic change. BigBank is attempting this through benchmarking initiatives. MutualCo has problems, particularly with the increase in risk that has to be managed. ExSociety senior managers cite an assumed link between improvisation and innovation, and are intentionally allowing employees the organizational and temporal space to learn from experimentation and improvisation. FinanceCo and DivestCo display little evidence of effective improvisational activity, and NewCo is at the opposite end of the continuum, encouraging improvisational activity at all levels within the organization. This is an area where the other organizations, with the exception of ExSociety, which has a set of forums that could assist in this area, tend to be weak. Table 8 maps the acceptance, application, and effectiveness of improvisation practices across the six organizations.

Findings from this study indicate that project and change managers embrace improvisation almost universally as a means of achieving change. Many managers, 
Table 8. Use of improvisation within the case study organizations

\begin{tabular}{cccc}
\hline & \multicolumn{2}{c}{ Use of Improvisation } & \\
\hline BigBank & Acceptance & Application & Effectiveness \\
MutualCo & Strong & Widespread & Poor \\
ExSociety & Strong & Widespread & Poor \\
FinanceCo & Growing & Growing & Improving \\
NewCo & Weak & Limited & Poor \\
DivestCo & Strong & Widespread & Improving/Good \\
\hline
\end{tabular}

across all six organizations, have strongly articulated opinions about the need to move away from agreed plans in order to execute that change. Indeed, managements may "...make a conscious decision to improvise as a means of creating more flexibility of behavior and more spontaneous decision making" (Chelariu et al., 2002: 141). Crossan and Sorrenti (1997: 155) see this as "...intuition guiding action in a spontaneous way." This is especially true within BigBank and FinanceCo, where improvisation is also seen as a means of circumventing intra and inter-organizational political resistance. It is also apparent that improvisation often takes place without senior management knowledge, especially within BigBank and FinanceCo.

Managers are however better able to support improvisation if it is bounded by some kind of limiting framework. This is supported by the literature; Brown \& Eisenhardt's (1997: 16) "limited structure", e Cunha et al's (1999: 318) "minimal structure", and Weick's (1998: 545) "guidelines". As the Financial Services sector is highly regulated, and tends to be risk averse (Brooks \& Dawes, 1999: 197), such a framework is usually based around the management of risk. It is also recognized that improvisation is more effective if mechanisms exist to

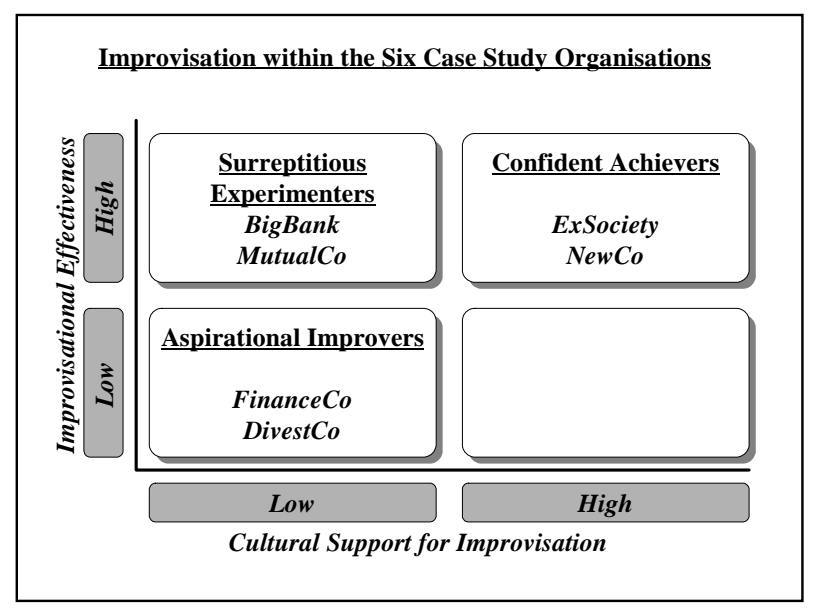

Figure 1. Matrix of the six case study organizations share successful improvisational activity (Moorman \& Miner, 1998b: 713; Chelariu et al., 2002: 142), and to communicate lessons learned from it to relevant parts of the organization that can benefit from such activity (Moorman \& Miner, 1998b: 713). This requires the development of organizational memory (Moorman \& Miner, 1998b: 713-714). Respondents within all the case study organizations voiced concerns about the ability of their organization to capture good improvisational practice and encapsulate it within such a memory for future use. Both ExSociety and NewCo have mechanisms to assist with this. In ExSociety improvisational activity is an enabler, and the management identifies and implements new improvisational processes as part of the streamlining of work processes. There is however evidence that the I.T.-based change initiatives do not include as much improvisational activity as initiatives to change operational processes. This is because more rigorous and defined procedures surround the implementation and testing of new IT-based systems, which provide the core account processing for most financial services organizations. NewCo, a significantly smaller and younger organization, uses improvisation at all levels, and has informal forums to identify and disseminate improvisational practices that have the potential to become "best practice" within the organization. There appears to be little evidence of such initiatives in the other four organizations, notwithstanding the rhetoric surrounding this activity in BigBank and MutualCo.

Within this study, the six case study organizations achieved different degrees of competence with their improvisational effectiveness, and their cultural support for improvisational activity. Figure 1 plots the case study organizations on a matrix that uses these two factors as the axes, using the evidence within the data as a basis for positioning. This distributes the organizations into three groups of two. The organizations where the data demonstrates a lower level of support for improvisation within the organizational culture and a low improvisational effectiveness quotient have been labeled "aspirational improvers", for their desire to improvise, albeit that this desire is moderated by lack of tangible support. Fi- 
nanceCo and DivestCo fall into this category.

Those organizations where the data indicates a lower level of support within the organizational culture for improvisational activity and a high improvisational effectiveness quotient appear to have token management support for experimentation and improvisation, but are not fully supportive of employees who fail to improvise effectively. Blame is often attached to failure, and this makes employees cautious in exposing their improvisation to management scrutiny. An element of surreptitiousness therefore also appears within this group of organizations, which comprises BigBank and MutualCo. These companies have been labeled "surreptitious experimenters". It is inevitable that an element of surreptitiousness prevails here, as improvisation requires participants to step away from the shared responsibility embedded in the "plan, then execute" paradigm, and to embrace individual unplanned activity, where failure to improvise effectively is very visible.

The third pair of organizations produced data indicating that they possess a high level of support for improvisation within their organizational culture and a high improvisational effectiveness quotient. Employees are supported and effective in their improvisational activity, and the culture allows learning from mistakes, and the capture of effective improvisational activity, both formally and informally. This group, which comprises ExSociety and NewCo, has been labeled "confident achievers". They manage change effectively using innovative processes, many of which are generated by the use of improvisation, and they have mechanisms to capture and disseminate such successful innovation to other areas of the organization.

\section{Conclusions}

There is very little literature pertaining to the use of improvisation within the implementation of project-managed change. There is compelling evidence that improvisation is used in this area, and project managers in all six organizations provide overwhelming support for improvisational activities as a means of executing change. Given the significant shift away from "command and control" based hierarchies, and towards trusted and empowered employees seeking opportunities to maximize profit, it is inevitable that partial reliance on intuition and creativity will encourage improvised solutions and interventions to assist with organizational transformation and change.

There is however a negative implication to improvising, particularly when applied to recent growth and failure within the financial services sector. Albrecht (1979) sees five significant areas of change in lifestyle notably: a move from rural living to urban living; a move from a stationary to a mobile society; a move from self-suffi- ciency to consumption; a move from isolation to interconnectivity; and a move from physically active to sedentary. This research centered around factors which cause stress in managers, informs the way people live, work, and manage their lives, and the way in which producers and service industries have to evolve in order to meet the needs of consumers. Specifically, sectors have had to evolve and change to service altering consumption patterns.

The social context of the U.K. retail financial services sector has been affected by Albrecht's factors, and through the 1990s and since the turn of the millennium this change has been accelerating, particularly in technological terms. It is however the move towards consumption driven by increased affluence in the advanced economies which has driven much social and cultural change and seen the emergence of consumerism, concern for equal opportunities, environmentalism, and other social movements which impinge upon the sector. This social change has also been instrumental in the development of new cultural norms.

The culture of an industry or sector is more difficult to define, but Gordon (1991: 398) suggests that “...it is possible for differences in values, or even assumptions, to exist within a company, as long as they do not undermine the basic assumptions on which the industry depends." This suggests that a sector or industry culture does exist, and it is considered that industry and sector are effectively interchangeable descriptors in this context. The basic assumptions upon which an industry or sector depends are the embedded core values and implicit rules to which component organizations within a given sector adhere. An example of a basic assumption that relates to U.K. retail financial services is fiscal responsibility. In the life insurance sub-sector this could be represented by an ability to pay claims when they fall due, and in the banking sub-sector it could be represented by an expectation that deposits could be repaid on demand. Whipp et al. (1989: 565) refer to these basic assumptions as logics of action. This view of logics of action at the sector level can be seen as an extension of the work of Bacharach and Lawler (1980), which has been developed and refined in Bacharach et al. (1996: 478). They argue that:

"...in essence, a logic of action may be seen as the implicit relationship between means and ends underlying the specific actions, policies and activities of organizational members. While the logic of action is for the most part taken for granted, it becomes manifest when parties try to explain themselves or justify to others the selection of specific means, ends, and the linkage between the two."

There is some common ground here with macrocultures (Abrahamson \& Fombrun, 1994), which link the cultural ambitions and expectations of managers within a sector, the existence of which has already been recog- 
nized. From the discussion of culture, there is a logical step to the consideration of culture change.

There are of course reasons why a change in culture within a sector may be desirable. Competitive issues have been at the forefront of change within many sectors, including U.K. retail financial services. Ezzamel et al. (1994: 22) document the move by U.K. financial services organizations from:

"...the established, highly bureaucratic administrative control that has long characterised the industry, engendering new forms of control based upon the twin ideals of empowerment and heightened accountability. Managers and staff alike are expected to become 'multiskilled' to facilitate organizational flexibility in the pursuit of 'quality'."

They suggest that much of this activity, which for public consumption is being carried out to improve customer service, is actually being carried out in the name of efficiency and cost saving to drive down the cost base.

However, in the Banking and Finance sector, these changes have resulted in evidence that the developing culture of personal gain over financial prudence has caused the sector to over-reach itself, ignoring the need to manage risk, and driving a desire for growth and short-term profit. This has been to the detriment of the aforementioned fiscal responsibility and financial prudence, and it is reasonable to suggest that the relaxation of controls and the reliance on, often misplaced, trust in traders and managers within the sector is largely to blame. During 2008 and 2009 there has been a degree of attrition, with stronger members of the sector absorbing weaker ones, and in U.K., this has been driven by vigorous government intervention. Unfortunately, many of the principles that underpin improvisational activity are likely to have contributed to the current situation.

\section{REFERENCES}

[1] E. Abrahamson and C. J. Fombrun, "Macrocultures: Determinants and consequences," Academy of Management Review, Vol. 19, No. 4, pp. 728-755, 1994.

[2] M. Agar, "The right brain strikes back in fielding," N.G. \& Lee R.M. (eds.), Using Computers in Qualitative Research London: Sage Publications, pp. 181-194, 1991.

[3] A. E. Akgun and G. S. Lynn, "New product development team improvisation and speed-to-market: An extended model," European Journal of Innovation Management, Vol. 5, No 3, pp. 117-129, 2002.

[4] K. Albrecht, "Stress and the Manager Englewood Cliffs," NJ: Prentice-Hall, 1979.

[5] S. B. Bacharach, P. Bamberger, and W. J. Sonnenstuhl, "The organizational transformation process: The micropolitics of dissonance reduction and the alignment of logics of action,” Administrative Science Quarterly, Vol. 41, No. 3, pp. 477-506, 1996.
[6] S. B. Bacharach and E. J. Lawler, "Power and politics in organizations,” San Francisco, CA: Jossey-Bass, 1980.

[7] N. Bacon, P. Ackers, J. Storey, and D. Coates, "It's a small world: Managing human resources in small businesses," International Journal of Human Resource Management, Vol. 7, No. 1, pp. 82-101, 1996.

[8] T. Baker, A. S. Miner, and D. T. Eesley, "Improvising firms: Bricolage, account giving and improvisational competencies in the founding process," Research Policy, Vol. 32, pp. 255-276, 2003.

[9] F. J. Barrett, "Creativity and improvisation in Jazz and organizations: Implications for organizational learning," Organization Science, Vol. 9, Vol. 5, pp. 605-622, 1998.

[10] F. J. Barrett, "Managing and improvising: Lessons from Jazz,” Career Development International, Vol. 3, No. 7, pp. 283-286, 1998.

[11] Brooks and J. Dawes, "Merger as a trigger for cultural change in the retail financial services sector," Service Industries Journal, Vol. 19, Vol. 1, pp. 194-206, 1999.

[12] S. L. Brown and K. M. Eisenhardt, "The art of continuous change: Linking complexity theory and time-paced evolution in relentlessly shifting organizations," Administrative Science Quarterly, Vol. 42, No. 1, pp. 1-34, 1997.

[13] A. Bryman, "Quantity and quality in social research," London: Unwin Hyman, 1988.

[14] C. Chelariu, W. J. Johnston, and L. Young, "Learning to Improvise, Improvising to Learn: A process of responding to complex environments," Journal of Business Research, Vol. 55, No. 1, pp. 141-147, 2002.

[15] T. Cooke-Davis, "The 'real' success factors on projects," International Journal of Project Management, Vol. 20, pp. 185-190, 2002.

[16] M. Crossan, "Improvise to innovate,” Ivey Business Quarterly, pp. 36-42, Autumn 1997.

[17] M. Crossan, "Improvisation in action,” Organization Science, Vol. 9, No. 5, pp. 593-599, 1998.

[18] M. Crossan and M. Sorrenti, "Making sense of improvisation in J. P. Walsh and A. S. Huff (eds.)," Advances in Strategic Management, Vol. 14, pp. 155-180, Greenwich, CT: JAI Press, 1997.

[19] M. P. Cunha e, J. V. Cunha da, and K. Kamoche, "Organizational improvisation: What, when, how and why," International Journal of Management Reviews 1, pp. 299-341, 1999.

[20] T. E. Deal and A. A. Kennedy, "Corporate cultures: The rites and rituals of corporate life,” London: Penguin Books, 1982.

[21] D. R. Denison, "Corporate culture and organizational effectiveness,” New York: John Wiley, 1990.

[22] D. R. Denison, "What is the difference between organizational culture and organizational climate? - A native's view on a decade of paradigm wars," Academy of Management Review, Vol. 21, No. 3, pp. 619-654, 1996.

[23] P. R. Dickson, "Marketing management (2nd Edition)," New York: The Dryden Press, 1997. 
[24] M. Eisenhardt, "Building theories from case study research,” Academy of Management Review, Vol. 14, pp. 532-550, 1989.

[25] M. Eisenhardt, "Strategic decisions and all that jazz," Business Strategy Review, Vol. 8, No. 3, pp. 1-3, 1997.

[26] Ezzamel, H. Willmott, and S. Lilley, "Changing management practices in financial services," Journal of General Management, Vol. 20, No. 1, pp. 22-28, 1994.

[27] J. R. Faulconbridge and D. Muzio, "Organizational professionalism in globalizing law firms," Work, Employment and Society, Vol. 22, No. 1, pp. 7-25, 2008.

[28] G. Fielding and R. M. Lee, "Computer Analysis and Qualitative Research,” London: Sage Publications, 1998.

[29] E. Freidson, "Profession of medicine: A study of the sociology of applied knowledge,” New York, NY: Harper \& Row, 1970.

[30] A. Friedman, "Responsible autonomy versus direct control over the labor process," Capital and Class 1, 1977.

[31] P. Frost and R. Stablein, [Eds.] "Doing exemplary research,” London: Sage Publications Ltd, 1992.

[32] E. Gardener, B. Howcroft, and J. Williams, "The new retail banking revolution,” Service Industries Journal, Vol. 19, No. 2, pp. 83-100, 1999.

[33] C. J. G. Gersick, "Time and transition in work teams: Toward a new model of group development," Academy of Management Journal, Vol. 31, pp. 9-41, 1988.

[34] G. G. Gordon, "Industry determinants of organizational culture,” Academy of Management Review, Vol. 16, No. 2, pp. 396-415, 1991.

[35] C. Handy, "Understanding organizations: managing differentiation and integration,” New York, Oxford University Press, 1993.

[36] J. Hatch, "Jazz as a metaphor for organizing in the 21st century,” Organization Science Vol. 9, No. 5, pp. 556-557, pp. 565-568, 1998.

[37] M. J. Hatch, "Exploring the empty spaces of organizing: How improvisational jazz helps redescribe organizational structure," Organization Studies, Vol. 20, No. 1, pp. 75-100, 1999.

[38] C. Heckscher, "Defining the post-bureaucratic type in C. Heckscher and A. Donnellon, (eds)," The Post- bureaucratic Organization: New Perspectives on Organizational Change Sage, Thousand Oaks, CA, pp. 14-62, 1994.

[39] K. M. Hmieleski and A. C. Corbett, "Improvisation as a framework for investigating entrepreneurial action," Unpublished Paper presented to the American Academy of Management Conference, Seattle, 1st-6th August, 2003

[40] A. M. Huberman and M. B. Miles, "Data management and analysis methods in K. M. Denzin \& Y. S. Lincoln (eds)," Collecting and Interpreting Qualitative Materials London: Sage Publications, pp. 179-201, 1998.

[41] M. Jelinek, L. Smircich, and P. Hirsch, "Introduction: A code of many colours,” Administrative Science Quarterly, Vol. 28, pp. 331-338, 1983.
[42] R. M. Kanter, "Strategy as improvisational theater,” MIT Sloan Management Review, pp. 76-81, Winter 2002.

[43] K. U. Koskinen, P. Pihlanto, and H. Vanharanta, "Tacit knowledge acquisition in a project work context," International Journal of Project Management, Vol. 21, pp. 281-290, 2003.

[44] J. M. Lehner, "Bricolage during implementation of strategies: Effects on flexibility,” Unpublished Paper presented to the American Academy of Management Conference, Toronto, 4th-9th August, 2000.

[45] S. A. Leybourne, "Project management and the implementation of strategic change within the UK financial services sector,” Unpublished Doctoral Dissertation: Cardiff Business School, 2002.

[46] S. A. Leybourne, "Improvising within management: Oxymoron, paradox, or legitimate way of achieving?" Unpublished Paper presented at the Academy of Management Conference, Honolulu, HI-5th-10th August 2005.

[47] S. A. Leybourne, "Managing improvisation within change management: Lessons from UK financial services," Service Industries Journal, Vol. 26, No. 1, pp. 1-23, 2006.

[48] S. Linstead, L. Fulop, and S. Lilley, "Management and organization: A critical text,” Basingstoke, Hants: Palgrave Macmillan, 2004.

[49] Lonkila, "Grounded theory as an emerging paradigm for computer-assisted qualitative data analysis in U. Kelle (ed.),” Computer-aided Qualitative Data Analysis: Theory, Methods and Practice, London: Sage Publications pp. 41-51, 1991.

[50] A. McLean and J. Marshall, "Intervening in cultures," University of Bath Working Paper, 1993.

[51] S. Mendonça, M. P. Cunha, J. Kaivo-oja, and F. Ruff, Wild Cards, Weak Signals and Organizational Improvisation Futures, Vol. 36, pp. 201-218, 2004.

[52] A. S. Miner, P. Bassoff, and C. Moorman, "Organizational improvisation and learning: a field study," Administrative Science Quarterly, Vol. 46, pp. 304-337, 2001.

[53] C. Moorman and A. S. Miner, "The convergence of planning and execution: improvisation in new product development,” Journal of Marketing, Vol. 62, No. 3, pp. 1-20, 1998.

[54] C. Moorman and A. S. Miner, "Organizational improvisation and organizational memory," Academy of Management Review, Vol. 23, No. 4, pp. 698-723, 1998.

[55] L. J. Mullins, "Management and organizational behavior (5th ed.)," Harlow, England: Financial Times/Prentice Hall, 1999.

[56] E. Ogbonna and L. C. Harris, "Managing organizational culture: Compliance or genuine change?” British Journal of Management, Vol. 9, No. 4, pp. 273-288, 1998.

[57] W. J. Orlikowski and J. D. Hofman, “An improvisational model for change management: The case of groupware technologies,” Sloan Management Review, Vol. 38, No. 2, pp. 11-21, 1997. 
[58] N. Pant and R. Lachman, "Value incongruity and strategic choice,” Journal of Management Studies, Vol. 35, No. 2, pp. 195-212, 1998.

[59] A. M. Pettigrew, "Longitudinal field research on change: Theory and practice," Paper presented at the National Science Foundation Conference on Longitudinal Research Methods in Organizations: Austin, TX, 1988.

[60] J. B. Quinn, "Strategies for change: Logical incrementalis,” Homewood, IL, Richard D. Irwin, 1980.

[61] D. Rollinson and A. Broadfield, “Organizational behavior and analysis: An integrated approach (2nd Ed.),” Harlow: Pearson Education, 2002.

[62] C. K. Russell and D. M. Gregory, "Issues for consideration when choosing a qualitative data management system," Journal of Advanced Nursing, Vol. 18, pp.1806-1816, 1993.

[63] G. Ryle, “On thinking,” Oxford: Basil Blackwell, 1979.

[64] E. H. Schein, “Organizational culture and leadership,” San Francisco, CA: Jossey-Bass, 1985.

[65] J. Seidel, "Method and madness in the application of computer technology to qualitative data analysis in fielding N. G. \& Lee R. M. (eds.),” Using Computers in Qualitative Research London: Sage Publications pp. 107-116, 1991.

[66] L. Smircich, "Concepts of culture and organizational analysis,” Administrative Science Quarterly, Vol. 28, No. 3, pp. 339-358, 1983.

[67] D. Stacey, "Complexity, creativity and management," Sa n Francisco, CA: Berrett-Koehler, 1996.

[68] E. Stake, “Case studies,” In K. M. Denzin \& Y. S. Lincoln [eds.], Handbook of qualitative research, pp. 236-247, London: Sage Publications, 1994.

[69] A. Sturdy, D. Knights, and H. Willmott, "Introduction: Skill and consent in the labor process in sturdy A., Knights D. \& Willmott H. (eds)," Skill and Consent: Contemporary Studies in the Labour Process, Routledge: London, 1992.
[70] J. Trethowan and G. Scullion, "Strategic responses to change in retail banking in the U.K. and the Irish Republic,” International Journal of Bank Marketing, Vol. 15, No. 2, pp. 60-68, 1997.

[71] M. L. Tushman, “Winning through innovation,” Strategy \& Leadership, Vol. 25, No. 4, pp. 14-19, 1997.

[72] Velez-Castrillon, D. M. Vera, and A. Kachra, "An improvisational model of strategic decision making," Unpublished paper presented at The Academy of Management Conference, Anaheim, CA-8th-13th August 2008.

[73] K. E. Weick, "The social psychology of organizing (2nd Ed.),” Reading, Mass: Addison-Wesley Publishing Company, 1979.

[74] K. E. Weick, "Improvisation as a mindset for organizational analysis,” Organization Science, Vol. 9, No. 5, pp. 543-555, 1998.

[75] E. A. Weitzman and M. B. Miles, "Computer programs for qualitative data analysis,” Thousand Oaks, CA: Sage Publications, 1995.

[76] R. Whipp, R. Rosenfeld, and A. Pettigrew, "Culture and competitiveness: Evidence from two mature UK industries,” Journal of Management Studies, Vol. 26, No. 6, pp. 561-585, 1989.

[77] Woolgar, "Configuring the user: The case of usability trials in Law J. (ed.),” A Sociology of Monsters: Essays on Power, Technology and Domination, London: Routledge pp. 57-99, 1991.

[78] D. Yanow, "Learning in and from improvising: lessons from theater for organizational learning," Reflections: Journal of the Society for Organizational Learning, Vol. 2, No. 4, pp. 58-65, 2001.

[79] R. K. Yin, "Case study research: Design and methods," London: Sage Publications Ltd, 1984.

[80] R. K. Yin, "Case study research: Design and methods [2nd Ed.],” London: Sage Publications Ltd, 1994. 